\title{
ALBINISMO E PRODUÇÃO DE SUBJETIVIDADE: uma análise dos diversos aspectos que compõem o tema
}

\author{
ALBINISM AND THE PRODUCTION OF SUBJETIVITY: an analysis of the \\ several aspects that make up the subject
}

Tatiana Oliveira Moreira*

\begin{abstract}
Resumo
O presente ensaio aborda aspectos importantes no cotidiano das pessoas com albinismo, como capacitismo, preconceito, pertencimento racial e acesso a políticas públicas. Tendo o objetivo de compreender como esses pontos têm relação com a imagem social e individual das pessoas com albinismo e como, consequentemente, afeta a produção de subjetividades. $\mathrm{O}$ albinismo gera oportunidade de discutir diversos elementos para além de parâmetros biomédicos, entretanto, ainda são raras as publicações acadêmicas que abarquem questões relacionadas à subjetividade. A partir da análise de referências bibliográficas, textos jornalísticos, artigos de portais de internet, documentos e legislações, realizou-se uma discussão que problematiza conceitos universais, hegemônicos para teorizar sobre subjetividade. Assim, o ensaio procura pautar a diversidade da vivência das pessoas com albinismo, elencando adversidades, as diferentes realidades e as potencialidades do público em questão.
\end{abstract}

Palavras-chave: albinismo; subjetividade; capacitismo; políticas públicas.

\begin{abstract}
This essay addresses important aspects in the daily lives of people with albinism, such as: disability, prejudice, racial belonging and access to public policies. Aiming to understand how these points have related to the social and individual image of people with albinism and consequently affect the production of subjectivities. Albinism provides the opportunity to discuss several elements beyond biomedical parameters. However, academic publications that cover issues related to the subjectivity of this portion of the population are still rare. From the analysis of bibliographical references, journalistic texts, articles from internet portals, documents and legislation, a discussion was carried out that problematizes universal, hegemonic concepts to theorize about subjectivity. Thus, I look for the essay seeks to guide in this essay the diversity of the experience of people with albinism, listing the adversities, the different realities and the potential of the public in question.
\end{abstract}

Keywords: albinism; subjectivity; ableism; public policy.

\section{Introdução}

No presente ensaio, abordo o albinismo, indo além das definições e referências biomédicas sobre o tema, inserindo os diversos contextos sociais que irão afetar os processos de subjetivação dos indivíduos com esta condição genética. Dentro do meu

\footnotetext{
* Mestra em Políticas Públicas e Formação Humana pela UERJ (PPFH/UERJ)/Brasil. Psicóloga no Tribunal de Justiça do Estado do Rio de Janeiro/Brasil. E-mail: tatiompsi@gmail.com.
} 
campo de atuação, que é a psicologia, problematizo as visões universalistas do que é ser humano, procurando auxílio teórico em abordagens que percebam a pluralidade dos sujeitos e das realidades sociais.

Meu interesse em produzir conhecimento em relação ao tema, vem da minha realidade como pessoa com albinismo. Na produção de minha dissertação de mestrado, trabalhando no campo da infância, deparei-me com metodologias científicas que não desprezam a inserção e afetação que o pesquisador sofre e provoca no campo de pesquisa. Há alguns anos venho compreendendo que não há neutralidade na pesquisa e na escrita; como aponta Lourau, somos afetados e afetamos o campo de estudo. Assim o autor, diz:

[...] a implicação deseja pôr fim às ilusões e imposturas da "neutralidade" analítica, herdadas da psicanálise e, de modo mais geral, de um cientificismo ultrapassado, esquecido de que, para o "novo espírito científico", o observador já está implicado no campo da observação, de que sua intervenção modifica o objeto de estudo, transforma-o. Mesmo quando o esquece, o analista é sempre, pelo simples fato de sua presença, um elemento do campo (LOURAU, 2004, p. 82-83).

Nesse sentido, a minha afetação diante do tema não tem o intuito de ser autobiográfica, mas é utilizada aqui para fornecer elementos que irão localizar meu lugar diante do assunto. Assim, conto também com uma análise documental e bibliográfica que fornece subsídios para abordar o albinismo na perspectiva da produção de subjetividade.

Os escritos acadêmicos sobre o albinismo ainda são incipientes no que diz respeito ao meu campo de atuação e estudos na psicologia e ciências humanas. Para a produção do presente ensaio, utilizei um conjunto de fontes documentais e bibliográficas que proporcionaram a análise dos diversos aspectos que podem compor a relação do albinismo com a subjetividade, tais como a questão da deficiência visual, o pertencimento racial, as relações interpessoais. Nesse sentido, foram utilizados produções acadêmicas, textos jornalísticos, legislações, livro autobiográfico, dados estatísticos fornecidos por documentos oficiais e textos de portais informativos na internet.

\section{A discussão da subjetividade para além do sujeito}

Por muitos anos, meu entendimento sobre o albinismo era dado pelo discurso de outras pessoas, assim como pelos olhares e opiniões. Apropriar-me do meu discurso a 
partir da minha vivência foi um movimento recente, assim como agregar conhecimento ao que sempre foi percebido por mim e por outras pessoas com albinismo.

Nesse momento, acredito ser pertinente abordar o conceito demonstrado por Djamila Ribeiro (2017), que fornece a possibilidade de localizar que minha escrita tem um lugar, de alguém que se apropriou criticamente e intelectualmente sobre aspectos estruturais da vivência em relação ao albinismo. Tal conceito promove a discussão de variados temas da sociedade a partir da localização social dos indivíduos. Não há a tentativa de limitar que somente determinados grupos podem falar sobre algum assunto, mas é fundamental a localização social de quem apresenta uma narrativa. Nesse sentido, Ribeiro aponta que:

Reduzir a teoria do ponto de vista feminista e lugar de fala somente às vivências seria um grande erro, pois aqui existe um estudo sobre como as opressões estruturais impedem que indivíduos de certos grupos tenham direito à fala, à humanidade. (RIBEIRO, 2017, p. 38).

A partir dessa localização de onde parte minha produção intelectual, adentro na discussão abordando referências sobre o tema da subjetividade. Para Guattari e Rolink (1996), a subjetividade não é algo intrínseco à natureza humana, é modelada e fabricada no registro do social. Para os autores, há uma separação entre os conceitos de indivíduo e subjetividade, pois percebem o primeiro como o resultado de uma produção de massa. “O indivíduo é serializado, registrado, modelado" (GUATTARI; ROLNIK, 1996, p. 31).

Nessa mesma perspectiva de romper com a ideia de indivíduo universal com uma essência única de ser humano, outros autores como Michael Foucault também se debruçaram em compreender os fatores políticos e sociais que afetam diretamente o que o autor cunhou como processos de subjetivação. Foucault (1995) elucida que seu objetivo de pesquisa era a compreensão "dos diferentes modos pelos quais, em nossa cultura, os seres humanos se tornaram sujeitos" (FOUCAULT, 1995, p. 231).

Neto (2004) aponta que a psicologia por muitos anos, e em muitas abordagens, seguiu e ainda segue um pensamento que classifica a subjetividade como interioridade, fazendo uma separação com o social, que seria a exterioridade. O autor faz uma análise dos escritos de Foucault sobre processos de subjetivação, em um dos trechos, ele aponta: 
A subjetividade entendida como emergência histórica de processos, não determinados pelo social, mas em conexão com os processos sociais, culturais, econômicos, tecnológicos, midiáticos, ecológicos, urbanos, que participam de sua constituição e de seu funcionamento. (FERREIRA NETO, 2004, p. 114).

O autor destaca que a noção de processos de subjetivação considera a processualidade em constante transformação, assim como sua constituição plural em detrimento de uma interioridade identitária. "Interessa pensar a subjetividade mais como processo que como estrutura. E também, como emergem, concomitantemente, novos modos de subjetivação ante os novos arranjos, na cidade contemporânea" (FERREIRA NETO, 2004, p. 114).

Assim, pretendo aqui não definir uma essencialidade da pessoa com albinismo, mas analisar os diversos aspectos que afetam os processos de subjetivação. A partir da leitura de Ferreira Neto (2004), foi possível apreender que não há um padrão da subjetividade, e ela também não é individualizada. Então, a ideia de uma "natureza humana" e universal desconsidera contextos, históricos, políticos, sociais e geográficos.

É fundamental fazer essa contextualização para se compreender que apesar de aspectos que aproximam as pessoas com albinismo, como a falta de melanina na pele, a baixa visão e a necessidade de cuidados com o sol, os processos de subjetivação se diferenciam a partir do contexto social, econômico, histórico e territorial de cada sujeito. Tal compreensão tenta alcançar uma análise que fale menos de estereótipos e mais das perspectivas que afetam o cotidiano das pessoas albinas, como o preconceito, a inserção em políticas públicas, o autocuidado, o capacitismo, o pertencimento racial, dentre outras perspectivas.

\section{A violência do preconceito e do capacitismo}

Uma das consequências que pode acometer as pessoas com albinismo é a baixa visão, condição que na maioria dos casos se enquadra entre as deficiências visuais. Assim como há diversidade em relação aos tipos de albinismo, há também diferenciações no que diz respeito à baixa visão, não havendo uniformidade na maneira como a condição irá se apresentar. Moreira e colaboradores descrevem: 
A pessoa com albinismo pode apresentar diferentes graus de deficiência visual, classificada de acordo com os valores de acuidade visual corrigida no melhor olho em: moderada (20/70 a 20/200); grave (20/200 a 20/400); profunda (acima de 20/400). Frequentemente ocorre estrabismo, com prejuízo na percepção de profundidade, pela falta de coordenação entre os olhos, fotofobia e nistagmo, devido aos movimentos rápidos e involuntários dos olhos na horizontal, que também contribui para a baixa visão. (MOREIRA, L. et al., 2007, p. 70).

A baixa visão está no caminho entre quem não tem deficiência visual e quem tem cegueira total; tal situação pode levar a não compreensão da condição. Por vezes, as pessoas com albinismo têm a sua limitação visual questionada e até negada, inclusive pela própria pessoa, familiares e outros.

Compreender minha condição visual como pessoa com deficiência aconteceu tardiamente, e não é raro encontrar relatos de pessoas albinas em entrevistas ou nas redes sociais descrevendo a falta de entendimento sobre a própria situação, assim como todas as dificuldades em relação à acessibilidade e inserção social. Apresento abaixo um trecho da reportagem de relatos de Ana Beatriz Ferreira, que fala de sua experiência com a deficiência visual e sua trajetória, no Portal G1 de 17 de maio de 2021:

\footnotetext{
Moradora da periferia na Zona Leste de São Paulo, Ana sempre estudou em escolas públicas.

No ensino fundamental, para enxergar a lousa, precisava se levantar e ficar bem perto dela - os óculos de grau não resolviam a dificuldade.

Foi só aos 13 anos que ela entendeu por quê: o albinismo não era apenas cutâneo, e sim ocular, causado por uma baixa síntese de melanina também nos olhos. Isso comprometia significativamente sua visão.

Descobrir, mesmo que tardiamente, que tinha uma deficiência foi determinante para lutar por novos direitos e recursos de acessibilidade. Passou a requisitar adaptações que facilitavam sua vida, como a ampliação nas letras das provas do Enem e dos vestibulares (TENENTE, 2021).
}

Relatos de desconhecimento, dificuldade escolar e no mercado de trabalho não são raros. A falta de acessibilidade em função da deficiência visual tem sido um grande obstáculo na vida das pessoas com albinismo. Assim, discutir sobre a deficiência é um ponto importante, pois a baixa visão atinge a maioria das pessoas albinas.

Os estudos da deficiência vêm passando há décadas por vários referenciais que abordam a forma como as pessoas com deficiência enfrentam barreiras diárias vivenciadas social e culturalmente. Diniz, Barbosa e Santos (2009) fazem uma genealogia dos estudos da deficiência, afirmam que apesar da deficiência ser uma das formas diversas 
dos corpos se apresentarem, sempre houve discriminação e um início tardio de estudos que abordassem o tema. Sobre esse histórico apontam:

\begin{abstract}
Essa redefinição da deficiência como uma combinação entre uma matriz biomédica, que cataloga os impedimentos corporais, e uma matriz de direitos humanos, que denuncia a opressão, não foi uma criação solitária da Organização das Nações Unidas. Durante mais de quatro décadas, o chamado modelo social da deficiência provocou o debate político e acadêmico internacional sobre a insuficiência do conceito biomédico de deficiência para a promoção da igualdade entre deficientes e não deficientes. (DINIZ, BARBOSA; SANTOS, 2009, p. 66).
\end{abstract}

Os autores acrescentam que a visão do corpo com deficiência, visto como anormal, advém do olhar médico que muitas vezes promove a dicotomia entre o normal e o patológico. Nesse sentido, podemos apreender que o modelo social dos estudos da deficiência pretende romper com essa dualidade do normal e anormal, buscando que as pessoas com deficiência possam vivenciar direitos, acessibilidade e inserção social em diversos âmbitos.

Há alguns anos foi possível conceituar essa discriminação em relação às pessoas com deficiência, e vem sendo utilizado o termo capacitismo, que segundo a autora Anahi Melo pode ser definido como:

\begin{abstract}
No caso do capacitismo, ele alude a uma postura preconceituosa que hierarquiza as pessoas em função da adequação dos seus corpos à corponormatividade. É uma categoria que define a forma como as pessoas com deficiência são tratadas de modo generalizado como incapazes (incapazes de produzir, de trabalhar, de aprender, de amar, de cuidar, de sentir desejo e ser desejada, de ter relações sexuais etc.), aproximando as demandas dos movimentos de pessoas com deficiência a outras discriminações sociais, como o sexismo, o racismo e a homofobia. Essa postura advém de um julgamento moral que associa capacidade unicamente à funcionalidade de estruturas corporais e se mobiliza para avaliar o que as pessoas com deficiência são capazes de ser e fazer para serem consideradas plenamente humanas. (MELLO, 2016, p. 3272).
\end{abstract}

O capacitismo é uma violência que faz parte do cotidiano das pessoas com deficiência e consequentemente da rotina de muitas pessoas com albinismo. Há a falta de materiais ampliados que tornem possível o acesso dos alunos com baixa visão na escola e em outros espaços. Além disso, é necessário se ter a preocupação com a luminosidade do ambiente, pois o excesso de claridade pode trazer incômodo em função da fotofobia que acomete alguns albinos. 
Em relação ao albinismo, essa zona do ver e não ver da baixa visão é diversa, com diferentes graus de acuidade, de campo visual, de percepção. Em um mundo capacitista e binário entre a visão total e a cegueira, como atender uma diversidade presente na baixa visão?

A tecnologia tem sido uma aliada nesse aspecto por meio da possibilidade de ampliar tamanho das fontes (letras) nos aparelhos celulares, nos computadores, além dos recursos de áudio, lupas e outros materiais. Para além das máquinas e recursos individuais, é necessário que as equipes nas escolas se preocupem com uma rotina de aprendizado acessível. Fato que não se caracteriza como favor e sim como direito, pois está previsto em legislação específica — Lei 13.146 de julho de 2015 —, conhecida como Lei Brasileira de Inclusão, que abarca também temas que já eram previstos em outras leis anteriormente.

Em texto publicado no Portal Geledés, descrevo como a discriminação e a falta de acesso pela deficiência podem afetar os processos de subjetivação:

\footnotetext{
Por vezes acreditamos que devemos nos desdobrar para conseguir ler ou realizar determinada tarefa, nos culpando e nos achando incapazes de exercer alguma função, quando na verdade não nos são dadas ferramentas de acesso. Uma escola por exemplo, não tem que atender somente quem tem $100 \%$ da visão, deve estar atenta à diversidade e dar possibilidade para que todos os alunos acessem o conteúdo.

A crença que a incapacidade é nossa se torna uma ferida na construção da nossa subjetividade com consequências que afetam a autoconfiança, o autoamor e as relações interpessoais. Por muito tempo me sentia mal por não conseguir ler algum material, agora entendo que determinada mídia não é acessível. $O$ capacitismo é causado por quem não promove acessibilidade e não por quem não consegue acessar. (MOREIRA, T., 2020).
}

Algumas pessoas conseguirão criar estratégias para transpor a falta de acessibilidade e avançar nos estudos, entretanto essa não é a realidade de muitos sujeitos com albinismo que acabam desistindo da escola ou não conseguem sustentar um objetivo que apresenta mais obstáculos que conquistas.

Ainda são incipientes os estudos sobre a inserção das pessoas com albinismo na educação. Um estudo realizado em Salvador com 80 famílias ligadas à Associação de Pessoas com Albinismo da Bahia (APALBA) mostrou dados em relação à escolaridade. $27,3 \%$ eram analfabetos, $35 \%$ chegaram ao ensino fundamental, $32,5 \%$ chegaram ao ensino médio e 5\% ao ensino superior (MOREIRA, L. et al., 2007, p. 73). Tais dados 
apresentam uma realidade de inserção nitidamente precária e excludente no ensino regular.

Outro obstáculo é o preconceito sofrido por estudantes com albinismo na escola por meio de xingamentos e apelidos pejorativos, que surgem em função da aparência desses estudantes que pode ser diversa dos demais alunos. O chamado bullying acontece como uma violência diária na vida de muitas crianças e adolescentes com albinismo, causando desmotivação para continuar a frequentar a escola. Roberto Bíscaro, em seu livro autobiográfico, "Escolhi ser albino", descreve algumas situações pelas quais passou, assim como o efeito nocivo na relação com o autorreconhecimento e o amor-próprio. $\mathrm{O}$ autor exemplifica esses momentos:

VOVÔ! PAPAI NOEL! RATO BRANCO! GASPARZINHO! LEITE AZEDO! BRANQUELO AGUADO! DOENTE! MARCIANO (embora jamais tenha sido verde)! Insultos berrados a plenos pulmões, individualmente ou em grupo. Eram para me tirar do sério e o conseguiam (BÍSCARO, 2012a, p. 99, grifos do autor).

Em menor ou maior grau, as pessoas com albinismo têm esses relatos como experiências traumáticas. Será muito difícil encontrar alguém com albinismo que tenha passado ilesa pelos olhares preconceituosos incapazes de lidar com a diversidade da apresentação dos corpos em uma sociedade. A diversidade é vista como diferença, e o diferente, como algo a ser discriminado. Até mesmo falar em diferença passa a ideia de que há algo "comum" ou "normal" e todo o resto é diferente. Acredito que a visão da diversidade abarca a imensidão de aparências possíveis.

O conteúdo já citado sobre processos de subjetivação dá subsídios para compreendermos que todos esses aspectos de uma cultura capacitista e preconceituosa são componentes para a relação que as pessoas com albinismo têm com diversos ambientes, assim como a visão que outras pessoas têm sobre a condição genética. $\mathrm{O}$ preconceito e o capacitismo são retroalimentados por falta de elementos fundamentais, como informação, diálogo e políticas públicas. Quando esse ciclo não é rompido, há a perpetuação de uma lógica de violência que marca as subjetividades.

Quando a evasão escolar acontece interfere em outro aspecto importante na constituição dos sujeitos que é a inserção no mercado de trabalho. A baixa escolaridade acarreta a diminuição das oportunidades para entrar na vida laboral, assim como 
influencia na remuneração que será recebida por alguma atividade. Muitas vezes, essas pessoas conseguirão apenas postos de trabalho com atividades subalternas e com baixos salários. Para as pessoas com albinismo que possuem ocupações que exijam exposição ao sol, o risco pode ser multiplicado, visto que esses indivíduos não apresentam a melanina como proteção da pele. Tal realidade acarreta a existência de pessoas jovens com lesões e câncer de pele, que em casos mais agressivos podem levar à morte.

Esse contexto atinge quase sempre pessoas com albinismo em condições socioeconômicas mais precárias. Tal ponto tem direta relação com a questão racial no Brasil, pois o albinismo é mais comum entre famílias negras, que em sua maioria ocupam os índices ligados à pobreza no país.

\title{
Albinismo e pertencimento racial: a negritude para além da cor da pele
}

Não há dados estatísticos sobre o albinismo no Brasil, há estimativas e alguns estudos regionalizados que dão subsídios para a inferência de que tal condição está mais presente entre famílias negras. Um estudo realizado na cidade de Salvador indicou que quase a totalidade das pessoas com albinismo daquela cidade são de ascendência negra.

\begin{abstract}
$\mathrm{Na}$ análise geral dos dados, nota-se que entre os bairros com maiores taxas de albinismo há frequência alta de etnia negra [...]. Entre os 10 bairros e localidades com maior taxa de afrodescendência, 6 destes (Ilha de Maré, Fazenda CXCoutos, Rio Sena, Lobato, Saramandaia, Alto das Pombas) apresentaram indivíduos com albinismo entre os seus moradores [...]. A taxa de afrodescendência nestes bairros e localidades apresenta percentuais de 92,99\% em Ilha de Maré até o mínimo de 89,29 \% no Alto das Pombas. (MOREIRA, S. et al., 2016, p. 25).
\end{abstract}

Os números relatados na Bahia estão em consonância com estimativas mundiais, como indica o relatório Pessoas com albinismo no mundo: uma perspectiva de direitos humanos, formulado pela nigeriana Ikponwosa Ero, perita independente da Organização das Nações Unidas sobre os direitos humanos das pessoas com albinismo:

O albinismo ocorre em todos os grupos raciais e étnicos do mundo, mas a proporção de pessoas afetadas pelo albinismo em uma determinada população varia por região. Na África, a prevalência de albinismo geralmente varia de uma pessoa em 5.000 a apenas uma pessoa em 15.000. Há relatos de que algumas populações selecionadas na África do Sul têm taxas de prevalência de até uma em mil pessoas. Até recentemente, a frequência do albinismo era estimada entre uma pessoa em 17.000 e uma pessoa em 20.000 na Europa e na 
América do Norte. No entanto, as pesquisas em andamento indicam que esses números podem ser arbitrários e não confiáveis, e que a prevalência de albinismo é, na verdade, muito superior em termos globais (ERO et al., 2021).

Esses dados fornecem base para a formulação de algumas associações ligadas às condições das pessoas com albinismo, que estando em maioria presente em famílias negras, sofrem as consequências do racismo estrutural ${ }^{1}$ que baliza a constituição da pirâmide social brasileira, deixando famílias negras em situação de pobreza. O documento do IBGE (2019), Desigualdades sociais por cor ou raça no Brasil, apresenta como a questão racial no Brasil está diretamente ligada à questão social. O estudo mostra que pessoas brancas ganham em média $73,4 \%$ a mais do que pessoas negras; entre a população mais pobre, $75,2 \%$ são de pessoas negras. O documento demonstra como essa desigualdade afeta a educação, o trabalho, a representação política, dentre outros aspectos que caracterizam a histórica disparidade entre os grupos raciais no Brasil.

Tal aspecto também afeta diretamente as pessoas com albinismo, que vivenciam com suas famílias a precariedade social tão comum no país. A falta de inserção em políticas públicas atinge pontos fundamentais para as pessoas com albinismo, como informações sobre o cuidado com a pele, com a visão, medidas de acessibilidade na educação, trabalho e lazer. A falta de informação pode levar também à discriminação e ao preconceito, assim como questionamentos sobre a paternidade de uma criança com albinismo.

Outro ponto importante na discussão sobre as relações raciais é o reconhecimento da negritude das pessoas com albinismo. Para muitas pessoas, tal questão pode parecer paradoxal, mas cabe a pergunta: Se essas pessoas não fossem albinas, qual seria a cor da sua pele? Cabelos, traços, pertencimento cultural e familiar não são elementos também importantes para o reconhecimento da negritude, além da cor da pele?

O racismo brasileiro sempre deu à negritude um lugar de inferioridade, deixando tudo que é relacionado aos negros como negativo. Tal ponto interfere também nas subjetividades negras, tanto das pessoas de pele mais escura quanto daquelas de pele mais

\footnotetext{
${ }^{1}$ Segundo Almeida (2018, p. 25), racismo é uma forma de discriminação sistemática baseada na raça, que de forma consciente e inconsciente define privilégios e desvantagens para indivíduos a depender de sua raça. $\mathrm{O}$ autor aborda que o racismo é estrutural afetando diretamente os aspectos históricos, sociais, econômicos, jurídicos e subjetivos na sociedade.
} 
clara, que muitas vezes negam a negritude se adequando a padrões estéticos, intelectuais e modos de vida brancos e europeus. Assim, muitas pessoas com albinismo, por já não carregarem a melanina na pele, podem tentar se encaixar no padrão da branquitude. ${ }^{2}$ Faço essa discussão no texto já citado do Portal Geledés:

Por 26 anos da minha vida alisei o cabelo e utilizei químicas para reduzir o volume. Assim como, por muito tempo queria fazer uma cirurgia para afinar o nariz. Que fenômenos operam nessas questões de afastamento da raça, que não o racismo estrutural?

Há uma prevalência do albinismo em famílias negras, então é necessário poder problematizar o lugar da pessoa com albinismo na identificação racial. Por muitos anos eu quis me afastar da negritude, e consequentemente do albinismo, ocupando um lugar de parecer "gringa" e atribuindo valor a essa classificação. (MOREIRA, T., 2020).

Sueli Carneiro aponta que há um reconhecimento da branquitude como policromática, já a negritude passa por inúmeras indagações (CARNEIRO, 2011, p. 66). A autora aponta ainda: "Uma das características do racismo é a maneira pela qual ele aprisiona o outro em imagens fixas e estereotipadas, enquanto reserva para os racialmente hegemônicos o privilégio de ser representados em sua diversidade." (CARNEIRO, 2011, $65)$.

Essa relação dissonante com a negritude pode produzir um "não lugar" na identificação racial das pessoas com albinismo, produzindo uma negação de si mesmo com consequências na relação consigo e com o outro. Uma posição que vai sendo construída desde a infância. Destaco outro trecho do texto do Portal Geledés:

Problematizar sobre a questão racial em relação ao albinismo diz respeito também à saúde mental e construção da subjetividade das pessoas albinas, principalmente na infância. Quando criança ou adolescente, eu não era a loirinha da turma, eu era a branquela de cabelo considerado ruim, nariz de batata e que não enxergava direito. Nunca me reconheci nas histórias infantis, a Cachinhos de Ouro tinha cachinhos como o meu, mas não era albina; e a Branca de Neve era branca como eu, mas tinha cabelo preto. Representatividade importa na construção da identidade de uma criança. Como me fez falta entender que meu pertencimento racial ia para além da cor da pele, que apesar dos questionamentos das pessoas, meus traços, meu cabelo, minha

\footnotetext{
${ }^{2}$ Schucman (2014) define como branquitude a posição de privilégio de um grupo no que se refere a acesso a recursos materiais e simbólicos.
} 
vivência cultural e de costumes familiares deixavam evidentes minha origem. (MOREIRA, T., 2020).

Neuza Santos Souza, em seu livro Tornar-se negro: as vicissitudes da identidade do negro brasileiro em ascensão social, publicado em 1983, elenca elementos que são essenciais aos estudos da relação do negro com a subjetividade balizada pelo racismo e os ideais instituídos pela branquitude. Ela informa também sobre a potência do reconhecimento da negritude para o psiquismo.

Saber-se negra é viver a experiência de ter sido massacrada em sua identidade, confundida em suas perspectivas, submetida a exigências, compelida a expectativas alienadas. Mas é também, e sobretudo, a experiência de comprometer-se a resgatar sua história e recriar-se em suas potencialidades. (SOUZA, 1983, p. 17-18).

Nesse sentido de recriar potencialidades, muitas pessoas albinas encontram no caminho da luta política e da interação coletiva a possibilidade de uma conexão potente com os processos de subjetivação.

\section{A inserção social como possibilidade de vida e cidadania}

A informação sempre será uma arma importante contra o preconceito e os estereótipos. Desde o início deste século, com a entrada da internet na residência das pessoas, foi possível circular informações e conexões para além do presencial. Fato que aconteceu com as informações sobre o albinismo, que saíram da monotemática genética da biologia e passaram a ocupar blogs, comunidades e grupos nas redes sociais, canais no Youtube, dentre outras formas de compartilhar e democratizar conteúdo.

Bíscaro (2012b) aborda esse tema fazendo um histórico dos agrupamentos virtuais e presenciais que começaram a surgir desde a década de 2000. O autor ressalta a importância da primeira comunidade surgida no extinto Orkut, as páginas que apareceram posteriormente no Facebook e Instagram, assim como seu próprio blog Albino Incoerente que desde a primeira década do século XXI apresenta reportagens, textos, relatos sobre o albinismo, assim como outros temas relacionados à arte. Bíscaro também destaca a importante representação que a APALBA, na Bahia, exerce como referência na luta por direitos e políticas públicas. 
Os encontros virtuais e presenciais possibilitam constituições subjetivas que promovem o encontro com experiências semelhantes, o reconhecimento de realidades parecidas, assim como o compartilhamento de práticas e modos de agir. Foi possível também a inserção nas universidades com trabalhos, projetos e pesquisas em contínuo processo, como por exemplo o de extensão da Escola de Enfermagem da UFRJ "As pessoas com albinismo e o direito à saúde" 3 , sob a coordenação da professora Nereida Lúcia Palko dos Santos.

Nesse panorama, uma questão fundamental para se destacar é a apropriação das pessoas com albinismo sobre suas pautas, sem ficar à mercê de uma produção de conhecimento e informação distante e verticalizada. A famosa frase utilizada pelo movimento social das pessoas com deficiência: "Nada sobre nós, sem nós", tem sido aplicada como direcionamento de atuação por muitas pessoas albinas, seja na atuação na busca por políticas públicas ou como circulação de informação na internet.

Toda essa democratização de conteúdo possibilitou encontros regionais e discussões a nível nacional. Na pandemia de COVID 19, iniciada em 2020, houve a intensificação da comunicação virtual de uma maneira geral, consequentemente tal contexto colaborou para a ampliação das informações sobre o albinismo via internet. Foram criadas mais páginas no Instagram e Youtube, além de uma atual articulação do Coletivo Nacional das Pessoas com Albinismo, que através do grupo em aplicativo de mensagens e reuniões virtuais, vem articulando estratégias para movimentar o Projeto de Lei $7762 / 2014^{4}$ que tramita no Congresso Federal desde 2014. No dia 29 de junho de 2021, aconteceu uma audiência pública na Câmara dos Deputados com representações regionais do Coletivo que apresentaram pontos importantes no que diz respeito à política de atenção integral às pessoas com albinismo.

Foucault, nos seus estudos sobre os processos de subjetivação, aponta que tais processos não ocorrem apenas pela sujeição a normas impostas, mas também por maneiras particulares de lidar politicamente com tais normas, que ele identifica como

\footnotetext{
${ }^{3}$ Disponível no endereço: https://sites.google.com/view/albinismoextensaoufrj.

${ }^{4}$ Tem como objetivo instituir a Política Nacional de Proteção dos Direitos da Pessoa com Albinismo. Para ver o projeto na integra: https://www.camara.leg.br/proposicoesWeb/fichadetramitacao?idProposicao $=619475$.
} 
possibilidade de uma subjetivação autônoma. Nesse sentido, o autor deu a seguinte resposta em um momento de entrevista:

É preciso distinguir. Em primeiro lugar, penso efetivamente que não há um sujeito soberano, fundador, uma forma universal de sujeito que poderíamos encontrar em todos os lugares. Sou muito cético e hostil em relação a essa concepção do sujeito. Penso, pelo contrário, que o sujeito se constitui através das práticas de sujeição ou, de maneira mais autônoma, através de práticas de liberação, de liberdade, como na Antiguidade a partir, obviamente, de um certo número de regras, de estilos, de convenções que podemos encontrar no meio cultural. (FOUCAULT, 2004, p. 291).

Nesse contexto de conexões coletivas, busca por direitos, quebra de imagens estereotipadas e construções de imagens a partir da própria experiência, a pessoa com albinismo tem a possibilidade de se apresentar no mundo não como as outras pessoas esperam, mas como ela deseja estar. A circulação de informações é importante para a autoimagem das pessoas albinas, mas também é fundamental para que outros indivíduos compreendam e vejam com mais naturalidade uma realidade que tem sido distorcida por visões preconceituosas e preconcepções.

É possível ler em relatos ou depoimentos em redes sociais que muitas pessoas com albinismo escutam que não parecem pessoas albinas, porque são bonitas. De tais relatos, podemos derivar questionamentos: Quando as pessoas com albinismo são consideradas bonitas, não parecem albinas? Que padrões estéticos operam para que pessoas com albinismo não ocupem o que é considerado belo? Os padrões estéticos impostos socialmente também interferem na construção da autoimagem dos sujeitos. Romper com a uniformização dos corpos e o estabelecimento de um padrão hegemônico promove conquistas importantes na relação das pessoas com suas características físicas.

Hoje, é comum ver nas redes sociais pessoas com albinismo expondo sua beleza e a diversidade da aparência das pessoas com esta condição genética. É possível testemunhar também a presença de modelos, homens e mulheres albinas participando de campanhas publicitárias e ensaios fotográficos.

Os questionamentos dos padrões estéticos, a apropriação das informações e da circulação de conteúdo promovem uma relação cada vez mais potente das pessoas albinas com sua imagem, seu repertório intelectual, assim como proporciona que outras pessoas possam estabelecer uma relação menos estereotipada e preconceituosa sobre o albinismo. 


\section{Considerações finais: a apropriação das nossas pautas é um caminho sem volta}

Por muitos anos o conhecimento sobre o albinismo se restringiu ao conhecimento biomédico, que embora também muito importante, não alcança toda a abrangência da diversidade das vivências das pessoas com albinismo.

Atualmente, tem sido possível acompanhar o crescimento da produção de conhecimento nas ciências humanas sobre albinismo, campo de saber fundamental na construção de análises que suplantam uma tentativa de uniformizar as pessoas albinas.

Acredito que os aspectos abordados neste artigo não se esgotam nos apontamentos feitos, sendo cada subtítulo deste texto merecedor de estudos futuros para aprofundá-los.

Abordar e produzir conhecimento nos temas como subjetividade, relações interpessoais, capacitismo e preconceito coloca a discussão sobre o albinismo para além dos conceitos biomédicos. Assim, o albinismo se desloca socialmente extrapolando os livros de biologia e genética, apresentando-se através de sujeitos ativos na construção de discursos que são essenciais para a formulação e inserção nas políticas públicas.

As pessoas com albinismo são e sempre foram tratadas preconceituosamente no Brasil, assim, a apropriação das narrativas, das lutas políticas e espaços de fala se constituem como estratégias primordiais para romper com o preconceito que por anos continua sendo uma questão sistemática no país.

\section{Referências}

ALMEIDA, S. L. O que é racismo estrutural. Belo Horizonte: Letramento, 2018.

BÍSCARO, R. R. Escolhi ser albino. São Carlos: Ed. EduFSCar, 2012a.

BÍSCARO, R. R. Albinos do meu Brasil: a luta para não passar em branco. Revista de História Oral - Oralidades. São Paulo, n. 11, p. 183-196, 2012b. Disponível em: https://diversitas.fflch.usp.br/sites/diversitas.fflch.usp.br/files/2019-09/Oralidades\%2011.pdf.

Acesso em: 2 nov. 2021.

BRASIL. Lei 13.146, de 6 de julho de 2015. Institui a Lei Brasileira de Inclusão da Pessoa com Deficiência (Estatuto da Pessoa com Deficiência). Brasília, DF: Presidência da República, [2015]. Disponível em: http://www.planalto.gov.br/ccivil_03/_ato2015-2018/2015/lei/113146.htm. Acesso em: 2 nov. 2021.

CARNEIRO, S. Racismo, sexismo e desigualdade no Brasil. São Paulo: Selo Negro Edições, 2011. 
DINIZ, D.; BARBOSA, L.; SANTOS, W. R. Deficiência, direitos humanos e justiça. SUR. Revista Internacional de Direitos Humanos. São Paulo, v. 6, n. 11, p. 65-77, 2009. Disponível em: https://www.scielo.br/j/sur/a/fPMZfn9hbJYM7SzN9bwzysb/?lang-pt\&format-pdf. Acesso em: 2 nov. 2021.

ERO, I. et al. Pessoas com albinismo no mundo: uma perspectiva de direitos humanos. Disponível em: Albinism_Worldwide_Report2021_PT.pdf (ohchr.org). Acesso em: 27 jul. 2021. Versão ampliada do relatório: Albinism Worldwide (número: A/74/190), enviado à Assembleia Geral das Nações Unidas em 2019.

FERREIRA NETO, J. L. Processos de subjetivação e novos arranjos urbanos. Revista do Departamento de Psicologia - UFF. Niterói, v. 16, n. 1, p. 111-120, 2004.

FOUCAULT, M. Uma estética da existência. In: MOTTA, M. B. (org.). Ética, sexualidade, política. Ditos e escritos V. Rio de Janeiro: Forense Universitária, 2004. p. 288-393. Original publicado em 1984.

FOUCAULT, M. Sobre a genealogia da ética: uma revisão do trabalho. In: RABINOW, DREYFUS. Michel Foucault: uma trajetória filosófica (para além do estruturalismo e da hermenêutica). Rio de Janeiro: Forense Universitária, 1995.

GUATARRI, F.; ROLINK, S. Micropolítica: cartografias do desejo. Petrópolis: Vozes, 1996.

IBGE. Informativo desigualdades sociais por cor ou raça no Brasil. Boletim Estudos e Pesquisas - Informação Demográfica e Socioeconômica. Rio de Janeiro, n. 41, 2019. Disponível em: https://biblioteca.ibge.gov.br/visualizacao/livros/liv101681_informativo.pdf. Acesso em: 2 nov. 2021.

LOURAU, R. Implicação e sobreimplicação. In: ALTOÉ, S. (org.). Analista institucional em tempo integral. São Paulo: Hucitec, 2004. p. 186-198.

MELLO, A. G. Deficiência, incapacidade e vulnerabilidade: do capacitismo ou a preeminência capacitista e biomédica do Comitê de Ética em Pesquisa da UFSC. Ciência \& Saúde Coletiva. Rio de Janeiro, v. 21, n. 10, p. 3265-3276, 2016. Disponível em: https://www.scielo.br/j/csc/a/J959p5hgv5TYZgWbKvspRtF/abstract/?lang-pt. Acesso: 2 nov. 2021.

MOREIRA, L. M. A. et al. Perfil do albinismo oculocutâneo no estado da Bahia. Revista de Ciências Médicas e Biológicas, Salvador, v. 6, n.1, p. 69-75, 2007. Disponível em: https://repositorio.ufba.br/ri/bitstream/ri/20475/1/9_v.6_1.pdf. Acesso em: 2 nov. 2021.

MOREIRA, S. C. et al. Estudo sobre albinismo oculocutâneo e etnia negra em bairros e localidades de Salvador-Bahia. Revista de Ciências Médicas e Biológicas, Salvador, v. 15, n. 1, p. 23-26, 2016. Disponível em: https://doi.org/10.9771/cmbio.v15i1.14224. Acesso em: 2 nov. 2021.

MOREIRA, T.O. Albinismo e relações raciais: subjetividade, pertencimento e aspectos sociais. Portal Geledés, publicado em 27 de outubro de 2020. Disponível em: https://www.geledes.org.br/albinismo-e-relacoes-raciais-subjetividade-pertencimento-e-aspectossociais/. Acesso em: 2 nov. 2021.

RIBEIRO, D. O que é lugar de fala? Belo Horizonte: Letramento, 2017.

SCHUCMAN, L.V. Sim, nós somos racistas: estudo psicossocial da sociedade paulistana. Psicologia \& Sociedade. Recife, v. 26, n. 1, p. 83-94, 2014. Disponível em: https://www.scielo.br/j/psoc/a/ZFbbkSv735mbMC5HHCsG3sF/?lang-pt. Acesso em: 2 nov. 2021. 
SOUZA, Neusa Santos. Tornar-se negro: as vicissitudes da identidade do negro brasileiro em ascensão social. Rio de Janeiro: Edições Graal, 1983.

TENENTE, Luiza. Negra, albina e com deficiência visual: ex-aluna da rede pública é aprovada em $1^{\circ}$ lugar nas cotas para psicologia na USP. Portal G1 - Educação, postado em 17 de maio de 2021. Disponível em: https:/g1.globo.com/educacao/noticia/2021/05/17/negra-albina-e-comdeficiencia-visual-ex-aluna-da-rede-publica-e-aprovada-em-1o-lugar-nas-cotas-para-psicologiana-usp.ghtml. Acesso em: 20 maio de 2021.

Recebido em: 20/07/2021.

Aceito em: 19/09/2021. 